\title{
Recurrent ventricular arrhythmias complicating myocardial infarction in the presence of phaeochromocytoma
}

\author{
A J McNeill, A A J Adgey, C Wilson
}

Waveney Hospital, Ballymena A J McNeil $C$ Wilson

Royal Victoria Hospital, Belfast A A J Adgey

Correspondence to Dr C Wilson, Waveney Hospital, Cushendall Road Ballymena BT $436 \mathrm{HH}$ Northern Ireland.

\begin{abstract}
After an acute myocardial infarction a 49 year old man developed late recurrent severe ventricular arrhythmias coincident with transient hypertensive episodes. A phaeochromocytoma was diagnosed on the basis of the urinary concentration of catecholamines and computerised tomography of the adrenal glands. After stabilisation of his cardiac rhythm and blood pressure with $\alpha$ and $\beta$ adrenergic blockade and antiarrhythmic treatment the right adrenal gland, which contained the tumour, was successfully resected.

The diagnosis of a phaeochromocytoma should be considered when recurrent ventricular arrhythmias are associated with intermittent hypertension after myocardial infarction.
\end{abstract}

A phaeochromocytoma is an uncommon tumour that it is important to diagnose because of the risk of hypertensive crises and malignancy. ${ }^{1-3}$ The most common symptoms are headache, palpitation, and sweating; and the combination of this triad with hypertension should raise the suspicion of a phaeo-

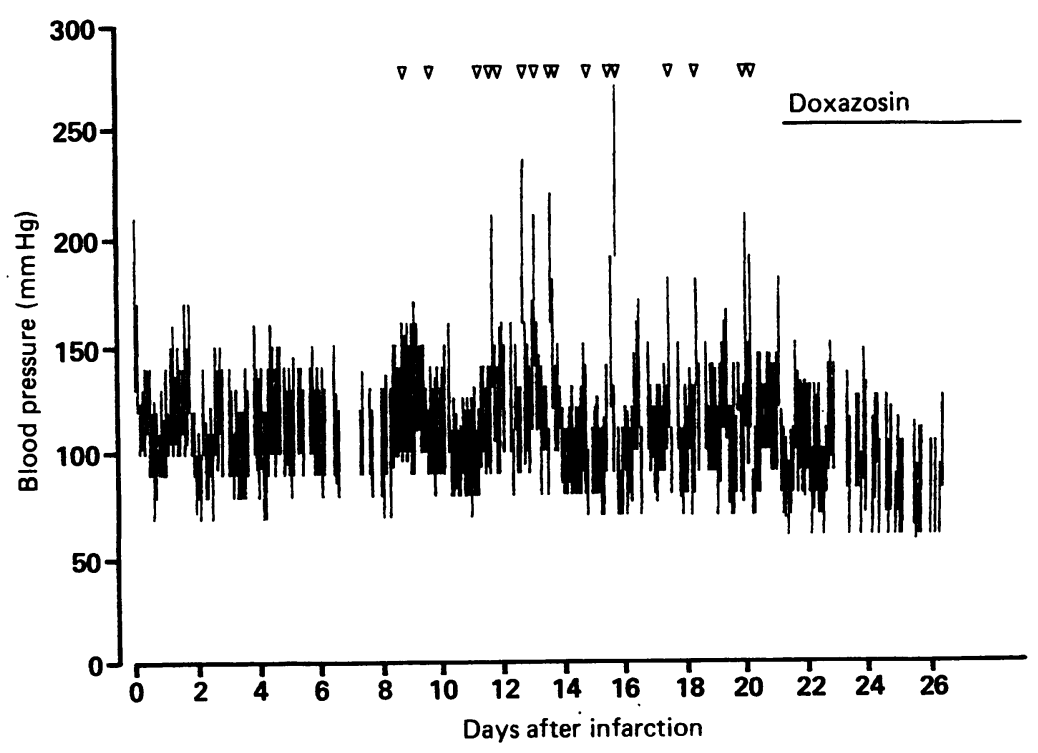

Blood pressure recordings during the first 26 days after infarction showing the relation between episodes of ventricular fibrillation $(\nabla)$ and fluctuations in blood pressure and the response to doxazosin. chromocytoma. ${ }^{145}$ The diversity of presentation, however, often delays the diagnosis, ${ }^{2}$ often with fatal results. We report a patient with an unusual presentation of this tumour.

\section{Case report}

A 49 year old man with no previous cardiac history was admitted by the mobile coronary care unit with an acute myocardial infarction. He had a one year history of hypertension and smoked 30 cigarettes a day. Thrombolytic therapy was not given because the initial blood pressure $(210 / 130 \mathrm{~mm} \mathrm{Hg})$ was so high. After pain relief by intravenous diamorphine he was treated routinely with oral propranolol (10 mg four times a day) and subcutaneous heparin (10 000 units twice a day). His blood pressure settled to $124 / 100 \mathrm{~mm} \mathrm{Hg}$ within two hours. The peak activity of serum creatine kinase was $2178 \mathrm{IU} / 1$ (normal < 180) (MB isoenzyme $297 \mathrm{IU} / 1$ (normal <25)).

Thirty six hours after admission the blood pressure rose again to around $170 / 100 \mathrm{~mm} \mathrm{Hg}$ and he developed atrial fibrillation with a fast ventricular response and short bursts of broad complex trachycardia. He reverted to sinus rhythm after treatment with digoxin. Four hours later he had bursts of ventricular tachycardia that recurred despite treatment with intravenous lignocaine and flecainide but settled after intravenous mexiletine. He continued to have occasional transient episodes of atrial fibrillation and ventricular extrasystoles with a rather fluctuating blood pressure until 10 days after admission when he collapsed with ventricular fibrillation which was easily corrected by direct current shock. Frequent episodes of ventricular fibrillation and ventricular tachycardia recurred over the subsequent 10 days (figure) despite successive treatment with lignocaine, mexiletine, procainamide, quinidine, amiodarone, and propafenone. Immediately after each episode his blood pressure was usually raised, often considerably, though it was relatively normal when his rhythm was stable. His basic sinus rhythm did not fluctuate unduly; usually it remained between 60 and 80 beats per minute.

Echocardiography showed infarction and aneurysmal dilatation of the left ventricular apex and lower septum. Twenty four hour urinary catecholamine excretion was 2.34 (nor- 
mal range $0.02-0.97) \mu$ mol, and assay showed increased excretion of noradrenaline (2302 nmol (normal 50-560)), adrenaline (29 nmol (normal 5-120)), and dopamine (639 $\mathrm{nmol}$ (normal 300-3900)).

Ultrasonography showed an enlarged right adrenal gland and this was confirmed by computerised tomography which showed a tumour measuring $4 \mathrm{~cm}$ by $2 \mathrm{~cm}$ in the right adrenal gland.

On day 21 after admission doxazosin ( $1 \mathrm{mg}$ daily) was introduced and treatment with amiodarone, propafenone, and metoprolol was continued. Within a few hours of the first dose both the heart rhythm and blood pressure became more stable (figure). Ventricular fibrillation did not recur though bursts of multifocal ventricular extrasystoles occasionally occurred and on day 29 there was one further prolonged episode of self-terminating ventricular tachycardia associated with transient hypertension $(200 / 120 \mathrm{~mm} \mathrm{Hg})$. When the dose of doxazosin was increased to $3 \mathrm{mg}$ daily good control of rhythm and blood pressure was restored. Thirty two days after admission he was transferred to the Royal Victoria Hospital Belfast for adrenalectomy. Doxazosin was replaced by phenoxybenzamine and his condition remained stable until the right adrenal gland, which contained a phaeochromocytoma, was removed 15 weeks after the initial presentation. Postoperatively he required high doses of noradrenaline, dopamine, and dobutamine and plasma expansion by rapid intravenous fluid infusion to maintain an adequate blood pressure. These were gradually reduced and when he was discharged six weeks after surgery he was normotensive, in sinus rhythm, and without medication.

At review five months after operation he was well apart from postural hypotension, which responded to xamoterol. Ambulatory electrocardiographic monitoring showed frequent benign but symptomatic ventricular extrasystoles that responded to propafenone. Electrophysiological studies showed no inducible arrhythmia. Urinary concentrations of catecholamines were normal.

\section{Discussion}

Patients with phaeochromocytoma can have atrial and ventricular arrhythmias associated with electrocardiographic changes that are consistent with acute myocardial ischaemia. ${ }^{67}$ Fatal myocardial infarction in a young man with undiagnosed phaeochromocytoma has been reported and his sudden death was presumably due to a fatal arrhythmia complicating the infarct. ${ }^{8}$ However, we are not aware of any previous case of such severe and persistent ventricular arrhythmias complicating myocardial infarction in the presence of a phaeochromocytoma.
Arrhythmias are so commonly accompanied by a reduction in blood pressure so the curious finding of hypertension with atrial fibrillation on the second day after infarction, and especially immediately after correction of most episodes of ventricular fibrillation, raised the suspicion of intermittent excessive catecholamine release. His life-threatening arrhythmias continued to recur despite treatment with numerous antiarrhythmic agents and $\beta$ adrenergic blockade and settled only after the addition of doxazosin, an $\alpha$ adrenergic blocking drug, to his treatment regimen. This response accorded with the predominant release of noradrenaline.

Catecholamine induced cardiomyopathy characterised by diffuse focal myocardial necrosis ${ }^{910}$ may be associated with electrocardiographic abnormalities resembling myocardial infarction ${ }^{911} 12$ but with normal coronary arteries. ${ }^{112}$ The clinical presentation in this case of classic chest pain, electrocardiographic changes, and raised serum enzymes in a heavy smoker was typical of coronary thrombosis with infarction. Intermittent excessive noradrenaline release presumably enhanced the arrhythmogenicity of the ischaemic myocardium.

Phaeochromocytoma is rare and can be fatal. This tumour should be suspected in any patient with recurrent arrhythmias associated with hypertension after acute myocardial infarction.

We thank Mr C Russell and Dr B Atkinson for their assistance in the management of this patient.

1 Gifford RW Jr, Kvale WR, Maher FT, Roth GM, Priestley JT. Clinical features, diagnosis and treatment of pheochromocytoma: a review of 76 cases. Mayo Clin Proc 1964;39:281-302.

2 Ross EJ, Griffith DNW. The clinical presentation of phaeochromocytoma. $Q J$ Med 1989;71:485-96.

3 Sheps SG, Jiang N-S, Klee GG, van Heerden JA. Recen developments in the diagnosis and treatment of pheochromocytoma. Mayo Clin Proc 1990;65:88-95.

4 Plouin PF, Degoulet P, Tugaýe A, Ducrocq M-B, Ménard J. Le dépistage du phéochromocytome: chez quels hyperLe depistage du phechromocyto 2585 hypert 11 ayant un phéochromocytome. Nouv Presse Med 11 ayant un phi

5 Bravo EL, Gifford RW Jr. Pheochromocytoma: diagnosis, localization and management. $N$ Engl J Med 1984; 311:1298-303.

6 Haas GJ, Tzagournis M, Boudoulas H. Pheochromocytoma: catecholamine-mediated electrocardiographic changes mimicking ischaemia. Am Heart $J$ 1988;116:1363-5.

7 Manning LV, Barratt S. Normotension, ventricular tachycardia and palpitation: an unusual presentation of phaeochromocytoma. Br J Clin Pract 1989;43:163-4.

8 Priest WM. Phaeochromocytoma with fatal myocardial infarction in a man aged 22. BMJ 1952;ii:860-2.

9 Van Vliét PD, Burchell HB, Titus JL. Focal myocarditis associated with phaeochromocytoma. $N$ Engl J Med 1966;274:1102-8.

10 Sardesai SH, Mourant AJ, Sivathandon Y, Farrow R, Gibbons DO. Phaeochromocytoma and catecholamine induced cardiomyopathy presenting as heart failure. $B r$ Heart $J$ 1990;63:234-7.

11 McGonigle P, Webb SW, Adgey AAJ. Phaeochromo cytoma: an unusual cause of chest pain. $B M J 1983 ; 286$ : 147-8.

12 Shaw TRD, Rafferty P, Tait GW. Transient shock and myocardial impairment caused by phaeochromocytoma crisis. Br Heart J 1987;57:194-8. 